This manuscript has been authored by UT-Battelle, LLC under Contract No. DE-AC05-00OR22725 with the U.S. Department of Energy. The United States Government retains and the publisher, by accepting the article for publication, acknowledges that the United States Government retains a non-exclusive, paid-up, irrevocable, worldwide license to publish or reproduce the published form of this manuscript, or allow others to do so, for United States Government purposes. The Department of Energy will provide public access to these results of federally sponsored research in accordance with the DOE Public Access Plan (http://energy.gov/downloads/doe-publicaccess-plan). 


\title{
An Atom Probe Perspective on Phase Separation and Precipitation in Duplex Stainless
}

\author{
Steels \\ Wei Guo ${ }^{1 *}$, David A.Garfinkel², Julie D. Tucker ${ }^{2}$, Daniel Haley ${ }^{3}$, George A. Young ${ }^{4}$, Jonathan D. \\ Poplawsky $^{11}$ \\ 1. Center for Nanophase Materials Sciences, Oak Ridge National Laboratory, Oak ridge, TN, USA. \\ 2. School of Mechanical, Industrial and Manufacturing Engineering, Oregon State University, \\ Corvallis, OR, USA. \\ 3. Department of Materials, University of Oxford, Parks Road, Oxford OX13PH, UK. \\ 4. Knolls Atomic Power Laboratory, Schenectady, NY, USA.
}

\begin{abstract}
Three-dimensional chemical imaging of $\mathrm{Fe}-\mathrm{Cr}$ alloys showing Fe-rich $(\alpha) / \mathrm{Cr}$-rich $\left(\alpha^{\prime}\right)$ phase separation is reported using atom probe tomography techniques. The extent of phase separation, i.e., amplitude and wavelength, has been quantitatively assessed using the Langer-Baron-Miller, proximity histogram, and autocorrelation function methods for two separate $\mathrm{Fe}-\mathrm{Cr}$ alloys, designated 2101 and 2205. Although the 2101 alloy possesses a larger wavelength and amplitude after annealing at $427^{\circ} \mathrm{C}$ for $100-10,000 \mathrm{hrs}$, it exhibits a lower hardness than the 2205 alloy. In addition to this phase separation, ultra-fine Ni-Mn-Si-Cu-rich G-phase precipitates form at the $\alpha / \alpha^{\prime}$ interfaces in both alloys. For the 2101 alloy, $\mathrm{Cu}$ clusters act to form a nucleus, around which a Ni-Mn-Si shell develops during the precipitation process. For the 2205 alloy, the Ni and $\mathrm{Cu}$ atoms enrich simultaneously and no core-shell chemical distribution was found. This segregation phenomenon may arise from the exact $\mathrm{Ni} / \mathrm{Cu}$ ratio inside the ferrite. After annealing for $10,000 \mathrm{hrs}$, the number density of G-phase within the 2205 alloy was found to be roughly one order of magnitude higher than in the 2101 alloy. The G-phase precipitates have an additional deleterious effect on the thermal embrittlement, as evaluated by the Ashby-Orowan equation, which explains the discrepancy between the hardness and the rate of phase separation with respect to annealing time [1].

\footnotetext{
${ }^{1}$ Corresponding author:

E-mail address.wguo2007@gmail.com (Wei Guo); poplawskyid@ornl.gov (Jonathan D. Poplawsky).
} 
Keywords: Atom Probe Tomography; phase separation; Cu cluster; G-phase; thermal embrittlement; Fe-Cr alloy

\section{Introduction:}

Inexpensive Fe-Cr based Duplex Stainless Steels (DSS), composed of ferrite and austenite, are considered promising structural materials because of a combination of good mechanical properties and corrosion resistance [2, 3]. These properties have enabled DSS for potential applications in power generation systems. However, long-term exposure to service temperatures between $300^{\circ} \mathrm{C}$ and $538^{\circ} \mathrm{C}$ leads to severe thermal embrittlement [4-6]. Several possibilities associated with the nanostructure and chemical changes within ferrite have been considered as the origin of the embrittlement. Firstly, the ferrite decomposes into Fe-rich $(\alpha)$ and Cr-rich $\left(\alpha^{6}\right)$ phases due to the miscibility gap of the Fe-Cr system. The $\mathrm{Cr}$ concentration and spacing of the $\alpha^{\prime}$ phase increases concurrently with the aging time $[4,7,8]$, leading to embrittlement. Secondly, Ni-Mn-Si-enriched G-phase prefers to form on the $\alpha / \alpha^{\prime}$ phase boundaries [8-10]. Previous transmission electron microscopy (TEM) experiments pinpointed that G-phase has a face centered cubic (FCC) structure with a complex unit cell of 116 atoms and a lattice parameter between 1.09 and $1.11 \mathrm{~nm}$ [10]. However, it is still under debate as to whether the G-phase plays an additional role in embrittlement [11]. A quantitative assessment on these two aspects is needed to tailor the alloying, design, and reliable life-span prediction of DSS. In this work, an atomically resolved chemical imaging technique, Atom Probe Tomography (APT), was used to quantify the extent of $\alpha / \alpha^{\prime}$ phase separation and G-phase formation to better understand the origin of thermal embrittlement of Fe-Cr alloys.

\section{Methods and Experimental Procedure}

\subsection{Materials Preparation}


Two plates of the two Fe-Cr alloys, 2101 and 2205, with a thickness of $2.54 \mathrm{~cm}$ were hot-rolled, solution-annealed above $1038^{\circ} \mathrm{C}$, and water quenched. A detailed chemical composition has been reported elsewhere [12]. After the production of the steel, five samples from each alloy were cut and aged isothermally in an air furnace at a temperature of $427^{\circ} \mathrm{C}$ for $1,100,1,000$, and 10,000 hrs, followed by air cooling. The desired service temperatures for DSS in power plant applications are near $300^{\circ} \mathrm{C}$. Due to the sluggish nature of the phase transformation accelerated tests are necessary. The temperature of $427^{\circ} \mathrm{C}$ was intentionally chosen to be above the service conditions to expedite the phase separation, so that extreme aging times were not required. Furthermore, this temperature was chosen to ensure it was below the $475^{\circ} \mathrm{C}$ nose of the embrittlement curve so that phase transformation mechanisms would be the same as lower temperature applications [5]. To perform the metallographic analysis and distinguish ferrite from austenite, the samples were mechanically polished and etched in $40 \% \mathrm{NaOH}$ for 10 s. Vicker's microhardness testing was performed in the ferrite grains with a $10 \mathrm{gf}$ load. The average hardness values for each sample with respect to aging time are shown in Table 1. Clearly, after annealing at $427^{\circ} \mathrm{C}$ for $100 \mathrm{hrs}$, alloy 2205 demonstrates significantly more hardening than the 2101 alloy. Though microhardness testing does not provide precise embrittlement behavior, it has been shown that microhardness changes with thermal aging correlate well to the loss of toughness seen in Charpy impact toughness testing $[5,6,12]$. APT was performed to rationalize a clear structure-property relationship within the ferrite for these two alloys.

\subsection{Atom probe tomography}

APT offers both three-dimensional (3D) imaging with sub-nm resolution and chemical identity of single atoms. APT can be used to quantify parameters such as the wavelength $(\lambda)$ and the change in $\mathrm{Cr}$ concentration $(\Delta \mathrm{Cr})$ between the $\alpha / \alpha^{\prime}$ phases that traditional high-resolution techniques can not resolve due to its ability to image all chemicals in $3 \mathrm{D}$ with equal probability. It 
is impossible to trace the structural evolution of interconnected ferrite by techniques such as electron backscatter diffraction (EBSD) because the initial stage of phase decomposition of the Fe-Cr alloys occurs at the nanoscale, as shown in Fig.1(a). Using a FEI Nova 200 focused ion beam (FIB) system and micromanipulators (Fig. 1(b)), the ferrite region of interest was extracted as a wedge, and mounted to a Si post array. A series of annular milling patterns were used to further sharpen the specimen into a needle shape with a diameter of less than $100 \mathrm{~nm}$ (Fig. 1(d)) [13]. After a 5kV low voltage milling step, the Si coupon with the sharpened needles was then transferred into the atom probe analysis chamber at a base temperature of $50 \mathrm{~K}$. The needle was then positioned within $\sim 40 \mu \mathrm{m}$ of the local electrode, in which a standing pulsed voltage are induced to enable the field evaporation of ions at specific moments in time, such that a time-of-flight mass spectrum can be produced. For these experiments, the voltage was pulsed with a frequency of $200 \mathrm{kHz}$, such that the atoms at the needle surfaces had enough energy to be pushed over the Schottky hump and were field evaporated and projected onto a position sensitive detector consisting of a microchannel plate and a cross-delay line. The evaporation rate used was $\sim 0.5 \%$. This setup allows for detection of both the time-of-flight of each ion (resulting in the mass-to-charge ratio), and their initial $x-y$ position with respect to the needle tip shape. The z-position is determined by the sequence of detection, which allows for an atom-by-atom 3D reconstruction of the decomposed ferrite with sub-nm resolution. The APT experiments were conducted using a CAMECA Instruments LEAP 4000X HR. At least 5 million ions were collected for each sample to ensure adequate data statistics. The datasets were reconstructed and analyzed using the IVAS 3.6.8 software (CAMECA Instruments) [14].

\section{Result and discussions}

\subsection{Nanostructure evolution during phase decomposition:}


The APT reconstruction of the fine scale microstructure evolution during the phase separation process $\left(1,100,1,000\right.$, and 10,000 hrs anneals at $\left.427^{\circ} \mathrm{C}\right)$ is shown in Fig. 2. $\mathrm{Fe}, \mathrm{Cr}$, $\mathrm{Cu}$, and $\mathrm{Ni}$ atoms are presented in pink, blue, orange, and green colors, respectively. The other elements are omitted for clarity. The lower images in Fig. 2 correspond to $2.5 \mathrm{~nm}$ thick slices extracted from the reconstruction, elucidating the nanoscale structure evolution from a rather homogeneous elemental distribution to a clear $\alpha / \alpha^{\prime}$ phase separation. Rather than having an interconnected $\alpha$ ' phase [15], the $\alpha$ ' phase forms isolated particles at 10,000 hrs due to the relatively low $\mathrm{Cr}$ content of $\sim 23.7$ at.\%. In addition, $\mathrm{Ni}$ - and $\mathrm{Cu}$-enriched phase formed in the vicinity of the $\alpha$ and $\alpha^{\prime}$ interfaces. The extent of the phase separation process is quantitatively evaluated using several different techniques described below that have their advantages and disadvantages for quantifying early- and late-stage phase separation.

\subsection{Wavelength determination of Fe-Cr phase separation:}

As shown in Fig. 2, the Cr-rich phase's composition and spacing continue to develop throughout

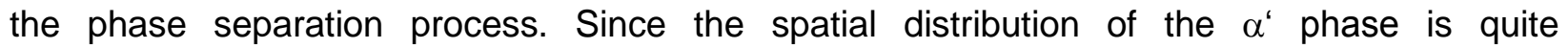
homogeneous and symmetric, a sinusoidal concentration variation fits well with the decomposition process. The wavelength $(\lambda)$ is determined by a measurement of the distances between $\mathrm{Cr}$ composition maxima within the compositional sine wave. The autocorrelation function $(A C F)$ is a versatile mathematical tool for quantifying the wavelength of the repeated sinusoidal $\mathrm{Cr}$ compositional profile, which is ideal for understanding the phase separation in three dimensions. The 3D radial autocorrelation function, $R_{k}$, can be expressed as [16]:

$$
R_{k}=\frac{1}{\sigma^{2}} \sum_{r=0}^{r_{\max -k}}\left(C_{r}-C_{0}\right)\left(C_{r+k}-C_{0}\right)
$$


where $C_{r}$ is the concentration of a spherical shell at radius $r$ from the chosen center point, $r_{\max }$ is the maximal radius over which the analysis is taken, $\sigma^{2}$ is the variance of the compositions given by $\sum_{0}^{r m a x}\left(C_{r}-C_{0}\right)^{2}$, and $C_{0}$ is the mean concentration of the element of interest. The first maximum peak represents the wavelength of the $\alpha^{\prime}$ phase, which is the distance where the $\mathrm{Cr}$ composition is most correlated with the central location [17].

Figure 3 (a) and (b) display small regions of interest of the APT volumes, which do not represent the average $\alpha$ - $\alpha$ 'separation distance for the datasets as a whole. On the other hand, the ACF was applied to the entire APT volume for each sample, and represents the average distance between $\alpha$ ' phases with a higher accuracy. In these data, a $0.1 \mathrm{~nm}$ shell thickness and a random sampling of $20 \%$ of the total ions were used. The data beyond the first maximum peak has little significance and are omitted for clarity. When aged at $427^{\circ} \mathrm{C}$ between $100 \mathrm{hrs}$ and $10,000 \mathrm{hrs}$ for the 2101 alloy, the wavelengths denoted by the first maximum peak are $4.8,7.6$, and $12.0 \mathrm{~nm}$ (Fig. 3(c)). For the same annealing conditions, the wavelengths for the 2205 alloy are 3.6, 6.6, and $7.2 \mathrm{~nm}$, respectively (Fig. 3(d)). The 2205 alloy exhibits a more sluggish phase decomposition, as confirmed by the comparison of $\mathrm{Cr}$ atom maps shown in Fig. 3(a,b). After annealing for $10,000 \mathrm{hrs}$, the $\mathrm{Cr}$ enriched regions tend to form as isolated Cr-rich clusters for the 2101 alloy, whereas the interconnected Cr-rich regions are still maintained for the 2205 alloy.

\subsection{Amplitude determination of Fe-Cr phase separation:}

The averaged peak-to-trough $\mathrm{Cr}$ composition $(\Delta \mathrm{Cr})$ was used to evaluate the amplitude of the decomposition. The Langer-Bar-on-Miller (LBM) method is one of the most common approaches to quantify $\Delta \mathrm{Cr}[18]$, and works well for low values of $\Delta \mathrm{Cr}$; however, the technique fails as $\Delta \mathrm{Cr}$ reaches values over $\sim 20$ at.\%, which will be discussed in more detail later. For the LBM method, the data is split into bins containing a set number of atoms, and the local composition is calculated within each bin (here we use 100 atoms/bin). The result is a frequency 
distribution histogram of the $\mathrm{Cr}$ concentration of each bin, which, for a dataset with two distinct phases, can be fit with a sum of two Gaussian distributions with the same compositional variance $\sigma$ :

$$
P(x)=\frac{1}{\left(x_{2}-x_{1}\right) \sqrt{2 \pi \sigma^{2}}}\left\{\left(x_{2}-x_{0}\right) \exp \left[\frac{-\left(x-x_{1}\right)^{2}}{2 \sigma^{2}}\right]+\left(x_{0}-x_{1}\right) \exp \left[\frac{-\left(x-x_{2}\right)^{2}}{2 \sigma^{2}}\right]\right\}
$$

where $x_{1}$ and $x_{2}$ are the element of interest compositions for the two Gaussian peaks, and $x_{0}$ is the average composition in the analyzed volume of the sample. The experimental histogram is thus represented by three parameters: $x_{1}, x_{2}$, and $\sigma$, and the composition amplitude $(\Delta \mathrm{Cr})$ is $x_{2}-x_{1}$

Fig. 4 shows the experimental frequency distribution overlaid with the LBM fit and the binomial distribution (the frequency distribution if $\mathrm{Cr}$ were randomly distributed throughout the dataset) of $\mathrm{Cr}$ atoms for alloy 2101. As the aging time increases, the phase separation can be visualized in the frequency distribution histograms as two Gaussian functions separating from each other, indicating that the 100 ion bins are detecting $\mathrm{Cr}$-rich and $\mathrm{Cr}$-poor phases. The extended $\mathrm{Cr}$ tails from the experimental data in the 1,000 hrs and 10,000 hrs aged conditions (Fig. 4(c,d)), which are a result of 100 ion bins encompassing phase borders, deviates the frequency distribution histogram from two Gaussian curves. Previous APT study of Fe-Cr binary alloys also showed that the amplitude values obtained from the LBM method are 5-15 at.\% Cr underestimated compared to the radius distribution function estimate [19]. For these late stage phase separation conditions, the LBM method is not ideal and another method must be applied to the data to quantify $\Delta$ Cr. To this end, a proximity histogram [20] of $\mathrm{Cr}$ isoconcentration surfaces was performed for the same APT dataset to obtain more accurate $\Delta \mathrm{Cr}$ values for late stage phase separation. For this method, 20 at.\% Cr isoconcentration surfaces were defined within the APT dataset to border the Cr-rich and Cr-depleted interfaces, which can be seen in Fig. 2. The proximity histogram was then calculated for these surfaces, which calculates a concentration 
profile with respect to distance from the isoconcentration surface for all solute atoms, and therefore, the compositional profile direction follows the surface normal. The results of the proximity histogram using 20 at.\% $\mathrm{Cr}$ isosurfaces for different aging times are summarized in Fig. 5. For the 10,000 hrs aged condition of the 2101 alloy, the maximum concentration of the $\alpha$ ' region calculated using the proximity histogram reaches $73.8 \pm 1.5$ at.\% compared to 46.0 at. $\%$ calculated from the LBM method, which confirms the underestimation of $\Delta \mathrm{Cr}$ for the LBM fit. It should be noted as well that the proximity histogram does not calculate $\Delta \mathrm{Cr}$ accurately for earlystage phase separation due to the challenge of distinguishing interfaces between Fe-rich and Cr-rich regions. Also, interfaces can be drawn between "random" statistical variations, which would overestimate the $\Delta \mathrm{Cr}$ value. For instance, defined interfaces using isoconcentration surfaces for randomly distributed data would reveal compositional variations in the proximity histograms. These compositional variations are due to interfaces being defined between random fluctuations in local compositions that fit to a binomial distribution, and are not statistically significant. Hence, these two approaches, LBM and proximity histogram analysis, should be jointly considered when assessing the exact amplitude of phase decomposition depending on the stage of the phase separation.

Fig. 6 summarizes the evolution of the amplitude, $\Delta \mathrm{Cr}$, with respect to aging time for both alloys. Initially, the $\Delta \mathrm{Cr}$ difference is small for both alloys; e.g., the $\mathrm{Cr}$ distribution is fairly homogeneous. For $100 \mathrm{hrs}$ aging, $\Delta \mathrm{Cr}$ nearly doubles. The decent fit to the data shown in Fig. $4(a, b)$ demonstrates that it is more appropriate to use data obtained from LBM. Hence, alloy 2101 shows a slightly higher $\Delta \operatorname{Cr}(12$ at.\%) than alloy 2205 (11 at.\%). For 1,000 hrs aging and beyond, the proximity histogram method is more accurate for describing the actual amplitude, which shows no difference between these two alloys. However, for a $10,000 \mathrm{hrs}$ annealing, $\Delta \mathrm{Cr}$ is 63.0 at.\% for the 2101 alloy, which is significantly higher than that (56.0 at.\%) for the 2205 alloy. 
The APT characterization reveals that both the amplitude and wavelength between the $\alpha-\alpha^{\prime}$ phases increases with aging time, as expected. However, the phase separation process of the 2101 alloy is much more pronounced than that for the 2205 alloy, as manifested by the larger values of $\lambda$ (Fig. 3) and $\Delta \mathrm{Cr}$ (Fig. 6), especially after 10,000 hrs annealing. Previous studies indicate that significant embrittlement is caused by a larger lattice mismatch due to the increase of Fe-Cr phase decomposition [21], shear modulus variation [21] or alteration of the moving dislocation morphologies [22]. However, as the aging time goes beyond 1,000 hrs, the hardness of the less decomposed ferrite (2205 alloy) is much higher than that in the 2101 alloy (Table 1 ), which is in contrast with previous predictions. Table 3 presents the composition of the $\alpha$ and $\alpha^{\prime}$ phases after aging between 100 and 10,000 hrs, as evaluated by proximity histograms. Different partitioning of elements, such as $\mathrm{Ni}$ and $\mathrm{Cu}$, will lead to a different kinetics and morphology of secondary phase precipitation, which potentially provides an additional hardening effect in ferrite. The extent of clustering inside these two alloys has been statistically quantified.

\subsection{G-phase precipitation behavior inside ferrite:}

The influence of G-phase on thermal embrittlement is still unclear [5, 23, 24]. In Fe-Cr alloys, the appearance of G phase is accompanied by Fe-Cr phase separation, which provides enough flux of constitutional atoms such as Ni, Mn, and Si. Previous APT works by Pareige et al. [24] suggest that the coarsening of $G$ phase has no influence on the microhardness of duplex stainless steel after $30,000 \mathrm{~h}$ ageing at $350^{\circ} \mathrm{C}$. However, the $\alpha-\alpha^{\prime}$ phase evolves concurrently with the G phase [25], and thus, the influence of the $\alpha-\alpha$ 'phase separation on the microhardness cannot be completely deconvoluted from the G-phase evolution. G-phase precipitates were also found in other steels such as irradiated reactor pressure vessel steels [26]. It was documented that sufficient G-phase-precipitate coarsening can reduce the hardness after thermal aging at $454^{\circ} \mathrm{C}$ for $168 \mathrm{hrs}$ [27], indicating that a fine distribution of G-phase 
contributes an additional hardening effect. Li et al. [11] has published an opposite view, in which they annealed the Fe-Cr steel sample above the miscibility gap, which removes the $\alpha / \alpha$ ' phase separation, but retains the G-phase precipitation within the matrix. The hardness of the annealed sample containing the G-phase was also reduced significantly. Contradictory observations like these have motivated a comparison of the precipitation behavior of the nanoscale G-phase with the material properties and $\alpha$ - $\alpha^{\prime}$ phase separation.

For small precipitates, APT uniquely provides a detailed characterization, including size, composition, number density, and volume density inside the 3D volume. Fig. 7 displays the various stages during the nucleation and growth of $\mathrm{Cu}-\mathrm{Ni}$ rich clusters as a function of aging time for the 2101 alloy. The $1 \mathrm{hr}$ aged sample exhibits a homogeneous distribution of $\mathrm{Ni}$ and $\mathrm{Cu}$ atoms. As the aging time proceeds to $100 \mathrm{hrs}$, very small and largely spaced Cu rich clusters appear inside the tip; however, the Ni distribution is still rather homogeneous (Fig. 7(b)). It has been suggested that local strain can induce Cu clustering in Fe-Cr alloys [28]. Hence, the Cu clusters are mostly found close to the $\alpha-\alpha^{\prime}$ phase domains possessing high misfit strain. From Fig. 7(c), it is observed that $\mathrm{Ni}$ also starts to cluster and the number density of $\mathrm{Ni}-\mathrm{Cu}$ rich clusters is at its maximum at 1,000 hrs, where the Ni atoms aggregate around the Cu clusters, forming a core-shell precipitate structure. After 10,000 hrs, the number of $\mathrm{Cu}-\mathrm{Ni}$-rich clusters decreases while the particle sizes start to increase, indicating that there is cohesion of the particles. Overall, the evolution of $\mathrm{Cu}-\mathrm{Ni}$ clustering occurs in three stages: stage I corresponds to the onset of $\mathrm{Cu}$ clustering; stage II relates to the $\mathrm{Cu}$ and $\mathrm{Ni}$ co-clustering with a Cu-rich core and Ni-rich shell structure; stage III manifests as the disappearance of small precipitates and the further growth of large precipitate via the Ostwald ripening mechanism [29].

Fig. 8 shows $1 \mathrm{~nm}$ thick atom maps of the center of selective clustering for the first two stages to further clarify the precipitation growth behavior. The major elements, i.e., Fe and $\mathrm{Cr}$, are not shown for clarity. In stage I (Fig. 8(a)), Cu atoms start to cluster in advance of all other non- 
major elements, i.e. $\mathrm{Ni}, \mathrm{Mn}$, and Si. A 2 at.\% $\mathrm{Cu}$ isosurface borders the cluster from the matrix, which is used to create a proximity histogram, shown in Fig. 8(c). The Cu concentration reaches 30 at. $\%$ within the precipitate, while the concentration of other elements remains consistent with that in the matrix, further elucidating stage I precipitate formation. For stage II, it is evident from Fig. 8(b) that $\mathrm{Cu}, \mathrm{Ni}, \mathrm{Mn}$, and $\mathrm{Si}$ atoms are also enriched around the precipitates such that the precipitates exhibit a core-shell elemental distribution. In Fig. 8(d), the proxigram analyses in terms of 10 at. $\% \mathrm{Cu}$ isosurfaces reveal that the solute levels reach $24.5 \pm 1.8$ at. $\% \mathrm{Ni}, 20.4 \pm 1.4$ at. $\% \mathrm{Mn}$, and $4.0 \pm 0.5$ at.\% Si at the precipitate-matrix interface.

The 2205 alloy exhibits a different precipitation behavior of the Ni-Mn-Si-Cu particles. At the onset of precipitation, initial Cu clustering is not observed before the other elements cluster. Instead, $\mathrm{Cu}$ and $\mathrm{Ni}$ atoms tend to cluster simultaneously and distribute homogeneously inside the precipitates. Fig. 9 shows an example of such a feature. After 10,000 hrs annealing, no core-shell structure was detected throughout the APT tip. As shown in the proxigram analysis in Fig. 9 (b), the selected precipitates display $37.2 \pm 4.2$ at. $\% \mathrm{Ni}, 19.1 \pm 3.3$ at.\% $\mathrm{Mn}, 6.4 \pm 1.6$ at.\% Si, and $5.2 \pm 1.2$ at.\% $\mathrm{Cu}$ inside the clusters. The absence of the core-shell elemental distribution is similar to the G phases previously observed in SAF 2507 steels [25].

The discrepancies of precipitates in the 2205 alloy from that in the 2101 alloy are mainly due to the higher $\mathrm{Ni}$ content or higher $\mathrm{Ni} / \mathrm{Cu}$ ratio within the ferrite. Table 3 provides the time dependent elemental partitioning inside ferrite. Also, the miscibility gap compositions of both alloys are evaluated by Thermo-Calc using only $\mathrm{Fe}, \mathrm{Cr}, \mathrm{Ni}, \mathrm{Mn}$, and $\mathrm{Si}$ elements. The calculations predict a significant partitioning of $\mathrm{Mn}$ in $\alpha^{\prime}$ phase and $\mathrm{Ni}$ in $\alpha$ phase. For the 2101 alloy, there are abrupt $\mathrm{Ni}$ concentration changes from 1.1 at.\% to 0.3 at. $\%$ in $\alpha$ phases, indicating that the diffusion of $\mathrm{Ni}$ atoms from the $\alpha^{\prime}$ phases determines the kinetics of G-phase

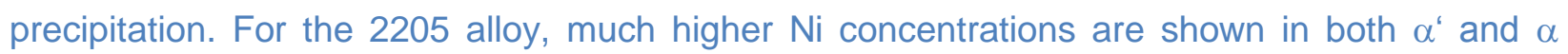
phases. The average Ni content inside the ferrite, as shown in Table 2, is $1.13 \pm 0.01$ at. $\%$ for the 
2101 alloy and $4.22 \pm 0.02$ at.\% for the 2205 alloy. In addition, the atom maps of $\mathrm{Ni}$ and $\mathrm{Cu}$ for the 2205 alloy display a larger particle density of precipitates than the 2101 alloy for the same condition. Much more precipitates form during the decomposition process in 2205 than the 2101 alloy, resulting in a higher precipitation hardening effect.

APT unambiguously provides the quantitative statistics for such precipitates, and thus allows for the quantification of the influence of particles on hardening. The parameters used for bordering the precipitates were identical for all the datasets (delocalization, $1.5 \mathrm{~nm}$; voxel size, $0.7 \mathrm{~nm}$; $\mathrm{Cu}$ cluster isoconcentration surface value 2 at.\%; Ni isoconcentration value, 7 at.\%). The average radius was calculated by the sphere-equivalent volume approach. Table 4 summarizes the average radius, number density, and volume fraction of the G-phase as a function of aging time. Upon isothermal aging at $427^{\circ} \mathrm{C}$, the average radius of the Ni-Mn-Si-Cu clusters in both alloys increases continuously from $\sim 1.3 \mathrm{~nm}$ to $>2 \mathrm{~nm}$. Note that the number density of the G-phase precipitates in the 2205 alloy is one order of magnitude higher than that in the 2101 alloy. According to the classic Ashby-Orowan equation [1], the stress increase contributing from the precipitation hardening is described as:

$$
\sigma_{p}=\frac{0.538 \cdot G b \cdot f_{v}^{\frac{1}{2}}}{d} \operatorname{In}\left(\frac{d}{2 b}\right)
$$

where $\sigma_{p}$ is the precipitation induced stress increase, $G$ is the shear stress of the steel $\left(8.16 \times 10^{4} \mathrm{MPa}\right), b$ is the burgers vector, $f_{v}$ is the volume fraction of particles, and $d$ is the diameter of the particles [1]. The stress increase can be easily converted into a hardness increase using the empirical relation: $H_{v} \approx 0.3 \sigma_{p}$ [30]. The calculated hardness value increases are also shown in Table 4. With a low G-phase volume fraction ( 0.01\%), no noticeable influence on the hardening is predicted, as the estimated hardness increase is only $3.5 \mathrm{HV}$. Overall, the stress increase due to precipitate formation for the 2205 alloy is much higher than that for the 2101 alloy because of the higher volume fraction of particles for each aging time. 
Therefore, additional hardening from the G-phase should be considered, although the G-phase formation is regarded as a byproduct of $\mathrm{Fe}-\mathrm{Cr}$ phase decomposition.

\section{Conclusions:}

Two series of Fe-Cr alloys, 2101 and 2205, were selected for studying the phase separation of ferrite after time-dependent, intermediate-temperature annealing by atom probe tomography. By characterizing the wavelength and amplitude of Fe-rich $(\alpha) / \mathrm{Cr}$-rich $\left(\alpha^{\prime}\right)$ phase decomposition, and G-phase precipitation, the main findings are as follows:

1. The expanded embrittlement effect from G-phase precipitation should be considered when evaluating the thermal embrittlement of duplex stainless steels. The AshbyOrowan stress analysis indicates that the increased hardness in 2205 compared to 2101 alloys arises from the larger number density of G-phase precipitates.

2. Although the hardness increase for the 2205 alloy is higher than the 2101 alloy after long time aging, a less enhanced phase separation behavior occurs for the 2205 alloy, as reflected by the smaller $\lambda$ and $\Delta \mathrm{Cr}$ values.

3. The LBM method can quantify the $\Delta \mathrm{Cr}$ value more accurately than the proxigram approach for evaluating the amplitude of phase separation in the initial stage because the proxigram approach suffers from bordering random statistical variations in addition to the $\alpha / \alpha^{\prime}$ interfaces, which artificially increases the $\Delta \mathrm{Cr}$ value. However, LBM underestimates the $\Delta \mathrm{Cr}$ value from a highly decomposed sample. Instead, the proxigram approach would be more accurate to assess the exact $\Delta \mathrm{Cr}$ when the samples are aged beyond 1,000 hrs.

4. The local chemistry and evolution procedure depends largely on the alloying elements within the ferrite. In the 2101 alloy with a $\mathrm{Ni} / \mathrm{Cu}$ atomic ratio as low as 6 , the $\mathrm{Cu}$-rich 
clusters serve as the nucleation sites for the G-phase precipitation, in which a Cu-rich core, Ni-Mn-Si-rich shell structure forms. For the 2205 alloy, with a $\mathrm{Ni} / \mathrm{Cu}$ ratio larger than 17.5 within the ferrite, the G-phase starts to form with the $\mathrm{Cu}$ and $\mathrm{Ni}$ atoms enriching simultaneously without the appearance of a core-shell distribution.

\section{Acknowledgements:}

The authors thank Dr. Hongbin Bei at Oak Ridge National Laboratory, Rosalia Rementeria at CENIM, and Ty Prosa at CAMECA Madison for fruitful discussions. This research was supported by ORNL's Center for Nanophase Materials Sciences (CNMS), which is a DOE Office of Science User Facility. 
Figure captions:
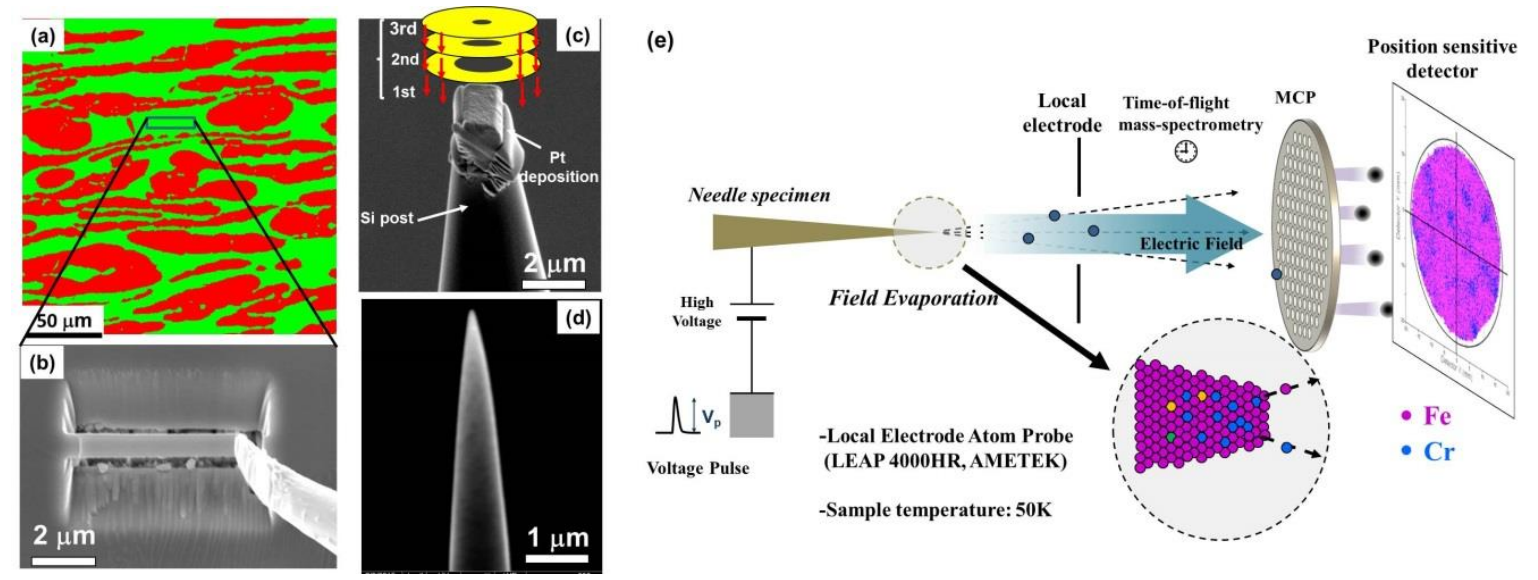

Figure 1. Phase-specific APT tip preparation in the ferrite phase in Fe-Cr alloys: (a) EBSD phase map showing the ferrite (green) and austenite (red); (b) SEM image showing the lift-out procedure by using micromanipulator in FIB; (c) series of annular milling steps by FIB; (d) Final shape of APT needle after $5 \mathrm{kV}$ ion cleaning; (e) schematic description of a local electrode atom probe.
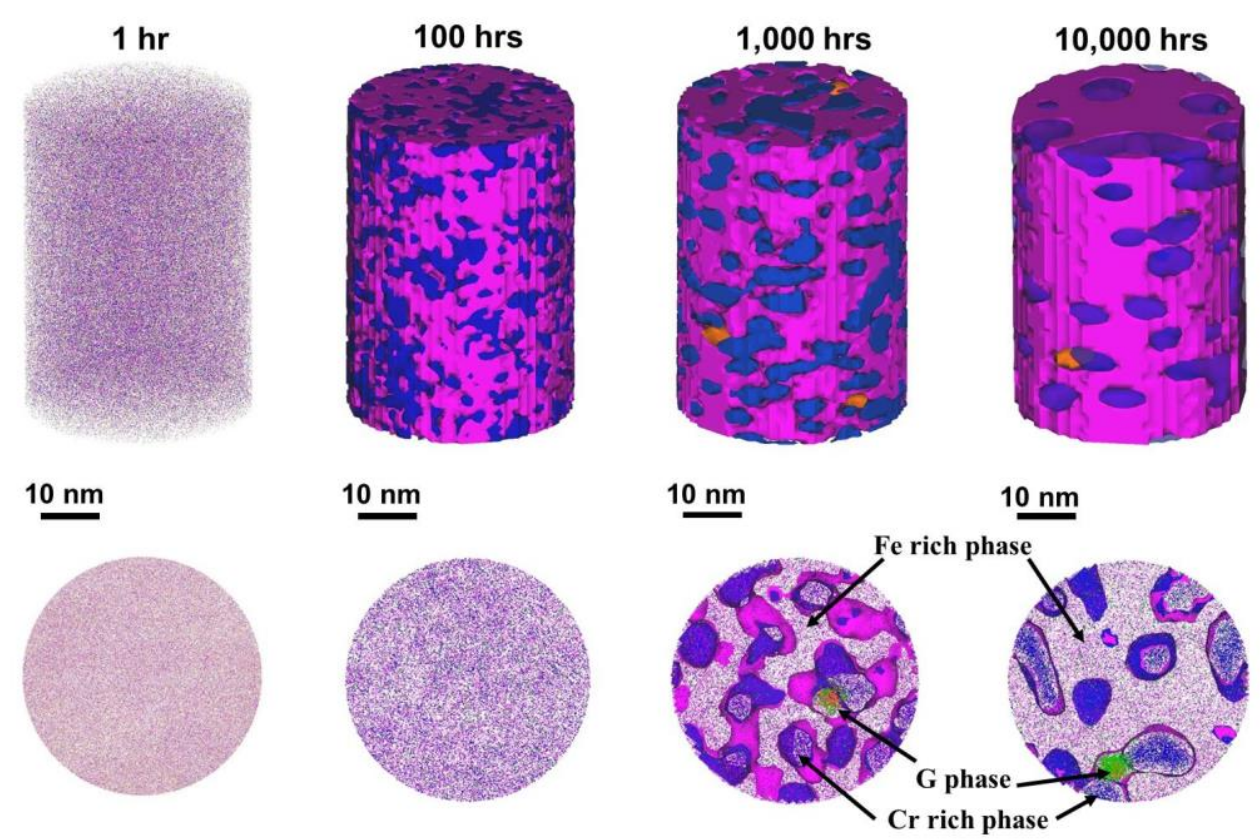

Figure 2. Evolution of phase separation as a function of annealing time in 2101 DSS. APT shows the main metallic elements distributions: $\mathrm{Fe}$ (pink), $\mathrm{Cr}$ (blue), $\mathrm{Ni}$ (green) and $\mathrm{Cu}$ (orange). The isoconcentration surfaces of $20 \mathrm{at} \% \mathrm{Cr}$ (blue) and $65 \mathrm{at} \% \mathrm{Fe}$ (pink) highlights the location of the $\alpha$ and $\alpha$ ' phases. Also shown are 10 at. $\% \mathrm{Cu}$ isosurfaces identifying the location of small G-phase precipitates. The lower images were $2.5 \mathrm{~nm}$ slices extracted from the reconstruction volume. 
(a)

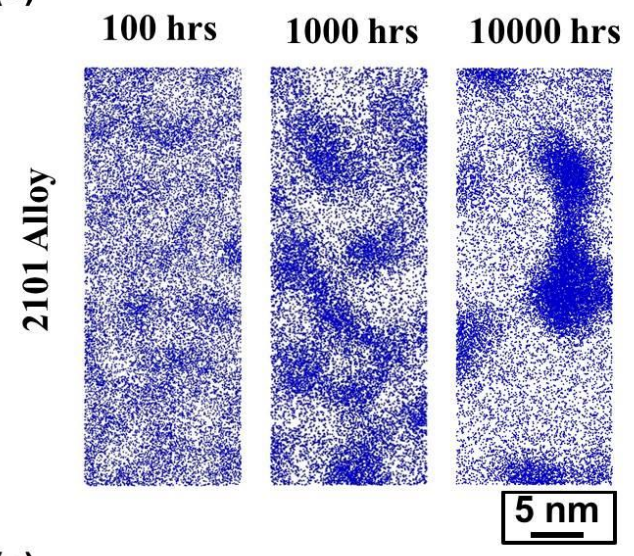

(c)

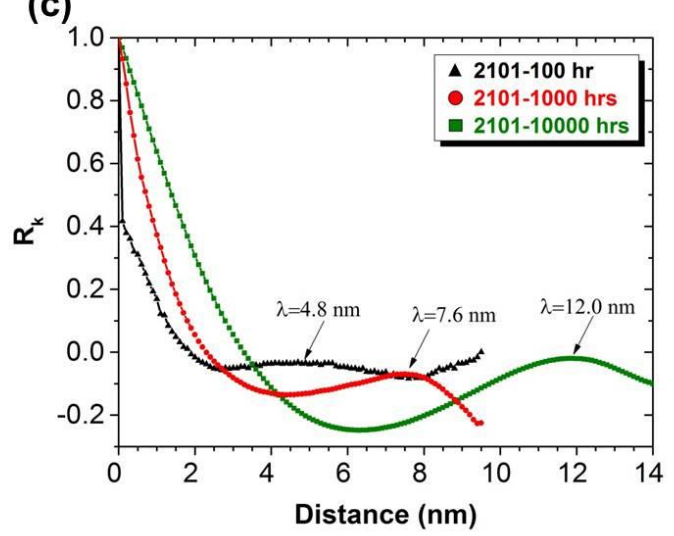

(b)

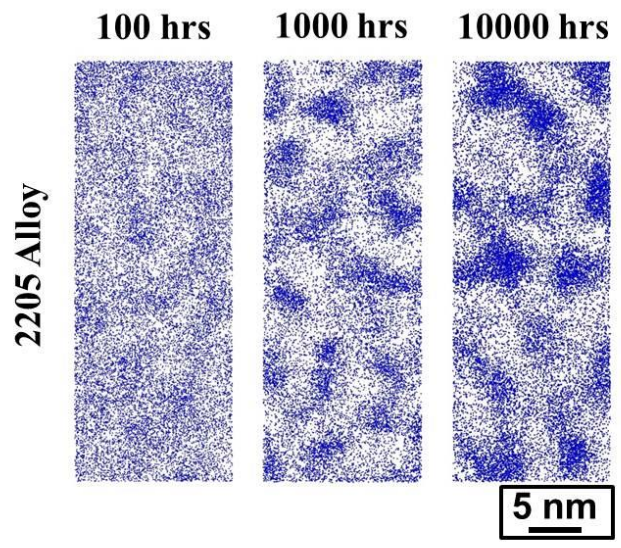

(d)

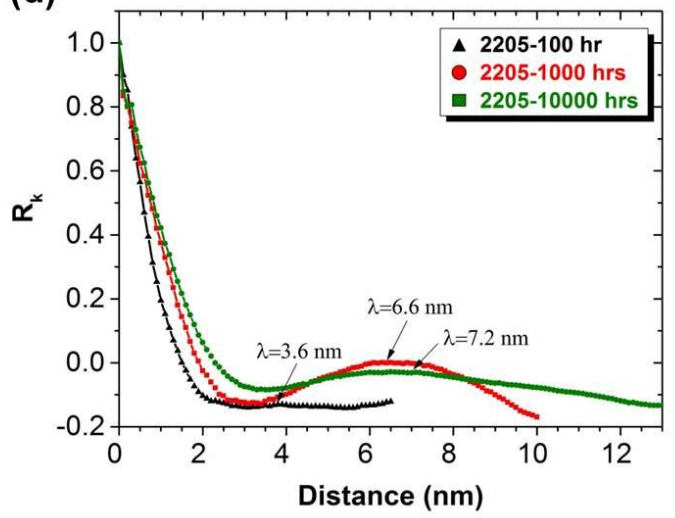

Figure 3. $40 \times 15 \times 5 \mathrm{~nm}^{3} \mathrm{Cr}$ atom maps for the 2101 alloy (a) and 2205 alloy after aging at $427^{\circ} \mathrm{C}$ for $100,1,000$, and $10,000 \mathrm{hrs}$. The corresponding autocorrelation function analysis is shown in (c) and (d). 

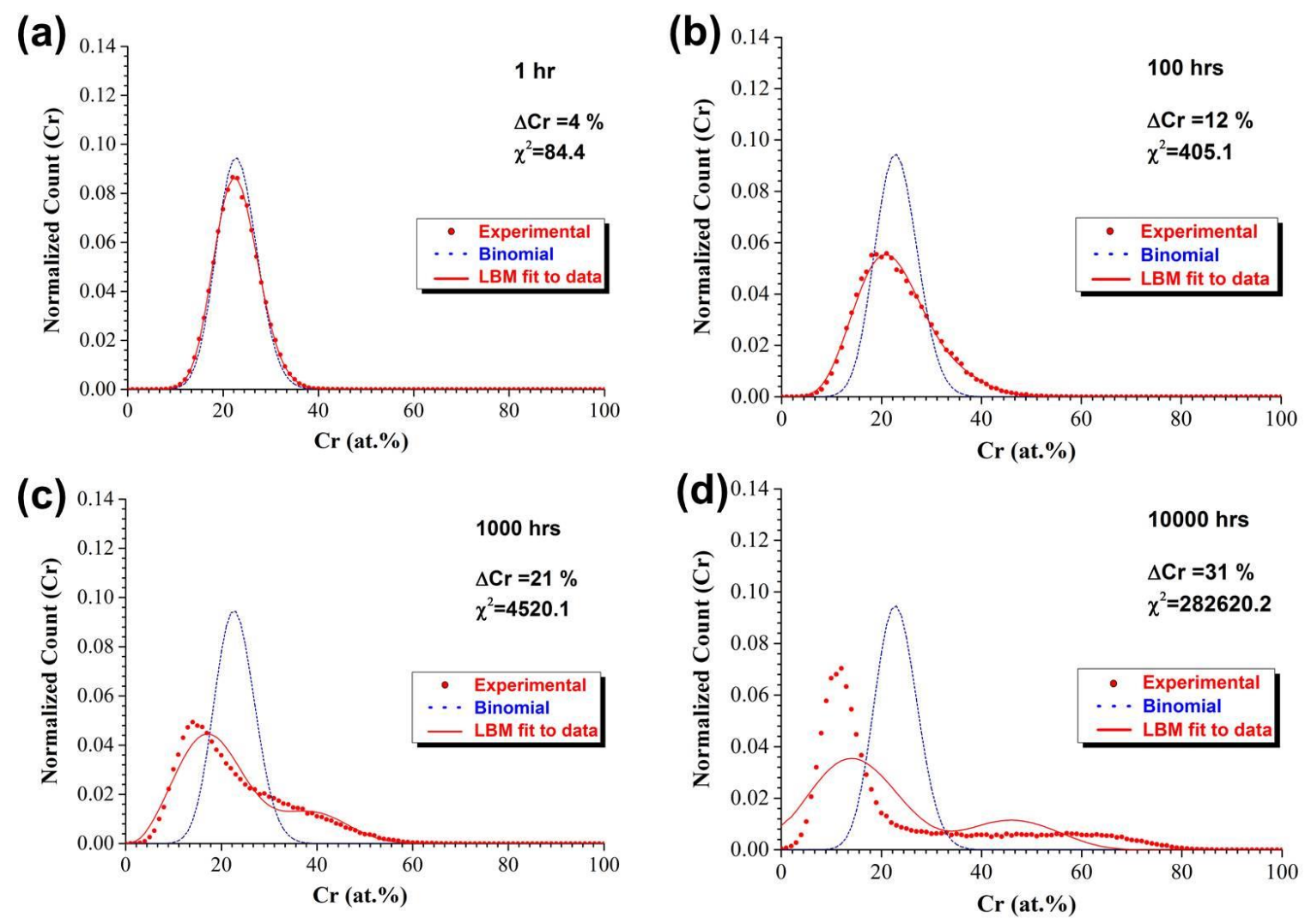

Figure 4. Experimental and binomial composition frequency distributions and the LBM fit for the 2101 alloy after aging at $427^{\circ} \mathrm{C}$ for between 1 and $10,000 \mathrm{hrs}$.

(a)

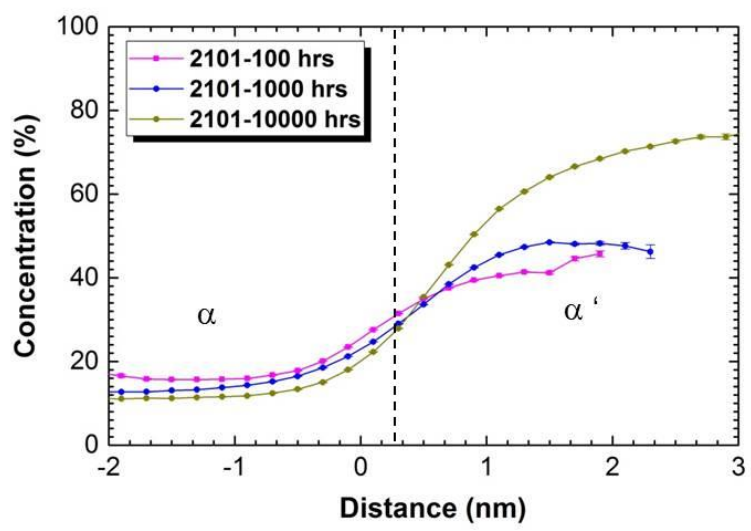

(b)

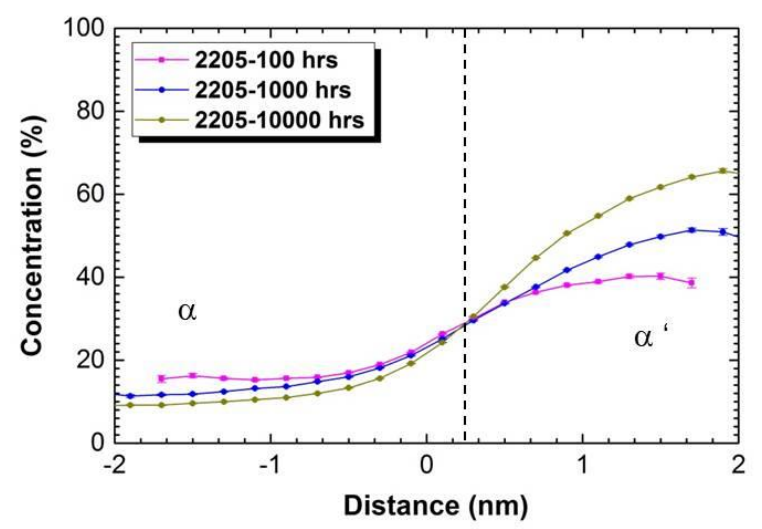

Figure 5. Proximity histogram of $\mathrm{Cr}$ atoms at all the $\mathrm{Cr}$-rich and Fe-rich interfaces in 2101 and 2205 duplex stainless steels. A drastic increase in the $\mathrm{Cr}$ content of the $\alpha$ ' region with aging time is shown. 


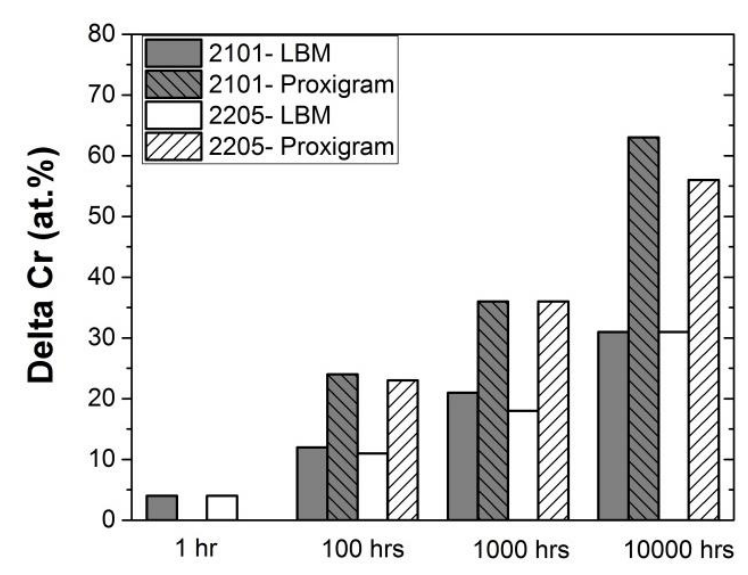

Figure 6. A summary of amplitude determination by LBM and proxigram analysis methods for 2101 alloys and 2205 alloys aged at $427^{\circ} \mathrm{C}$.

(a)

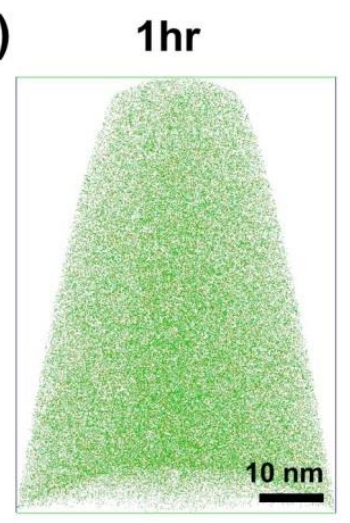

(c)

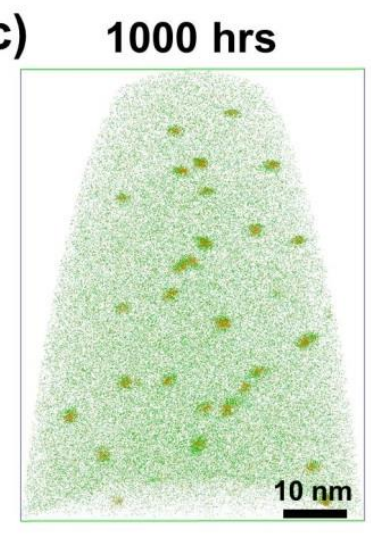

(b)

$100 \mathrm{hrs}$

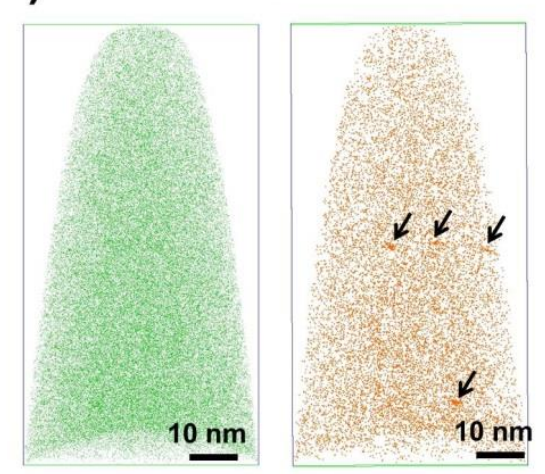

(d) $10000 \mathrm{hrs}$

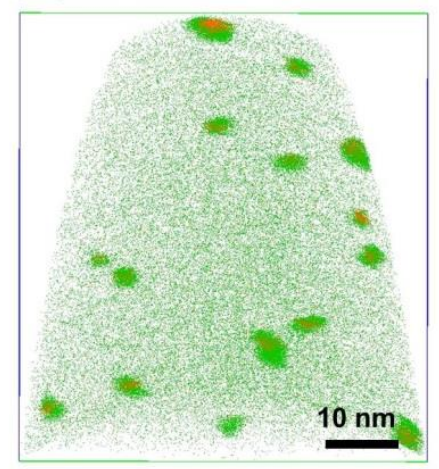

Figure 7. APT elemental maps of $\mathrm{Cu}$ (orange) and $\mathrm{Ni}$ (green) atoms of the 2101 alloy aged at $427^{\circ} \mathrm{C}$ for different times: (a) $1 \mathrm{hr}$; (b) $100 \mathrm{hrs;} \mathrm{(c)} \mathrm{1,000} \mathrm{hrs,} \mathrm{and} \mathrm{(d)} \mathrm{10,000} \mathrm{hrs.} \mathrm{The}$ arrows in (b) mark the positions of initial Cu clustering. 
(a)

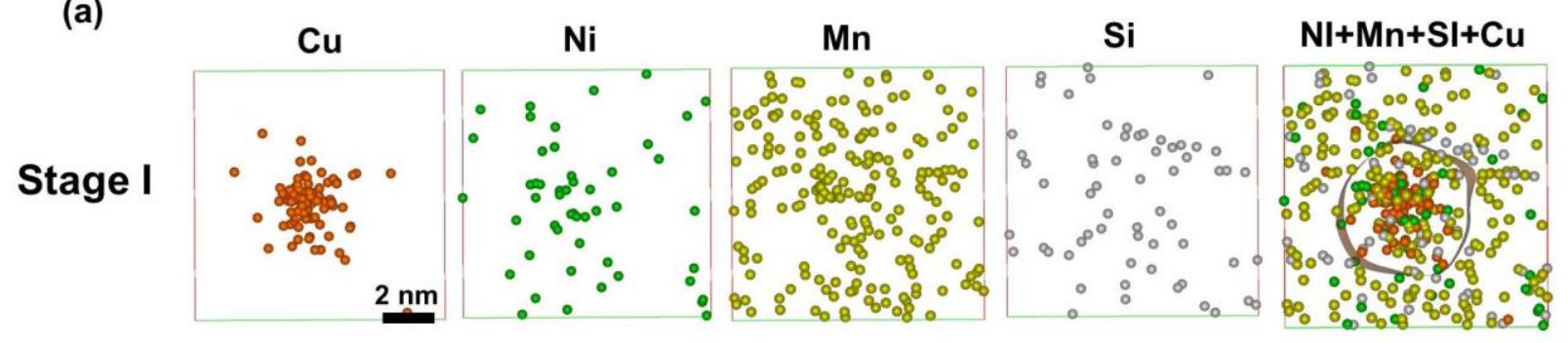

(b)
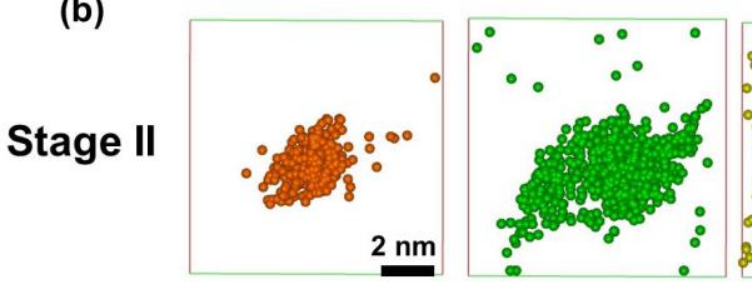

Stage I

(c)

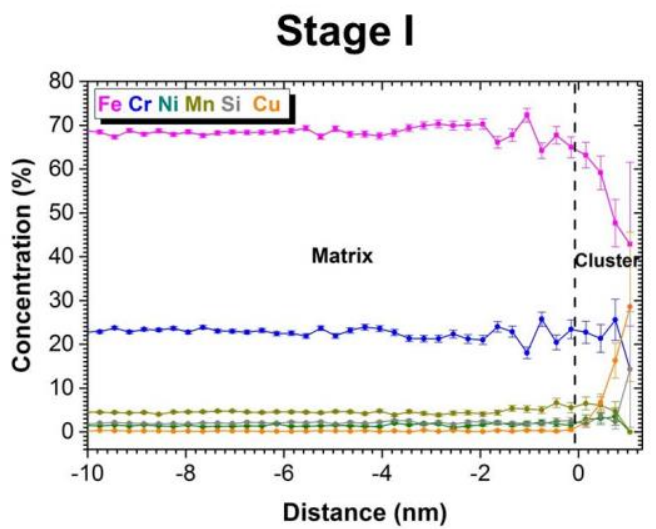

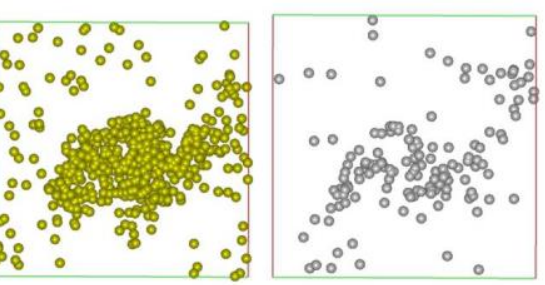

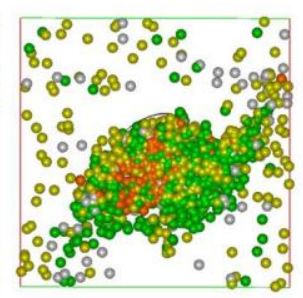

Stage II

(d)

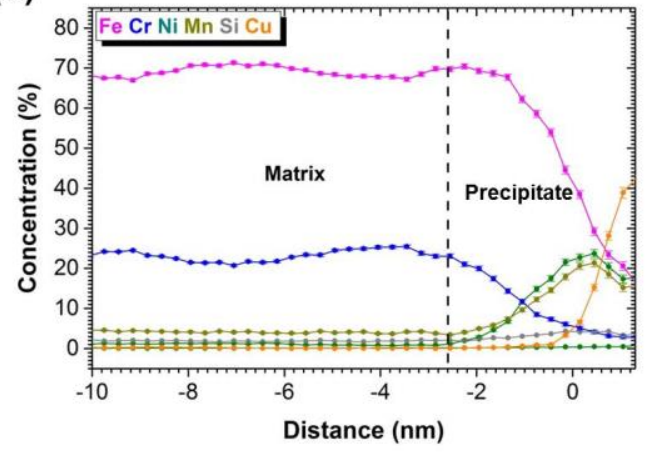

Figure 8. 1-nm-thick maps showing two stages of forming the Ni-Mn-Si-Cu precipitates $(a, b)$ in the 2101 alloy and proximity histograms of 2 at.\% $\mathrm{Cu}$ isosurfaces at two different stages (c,d). The dashed line in (c) and (d) mark the potential interfaces between the cluster (precipitate) and the matrix. 
(a)

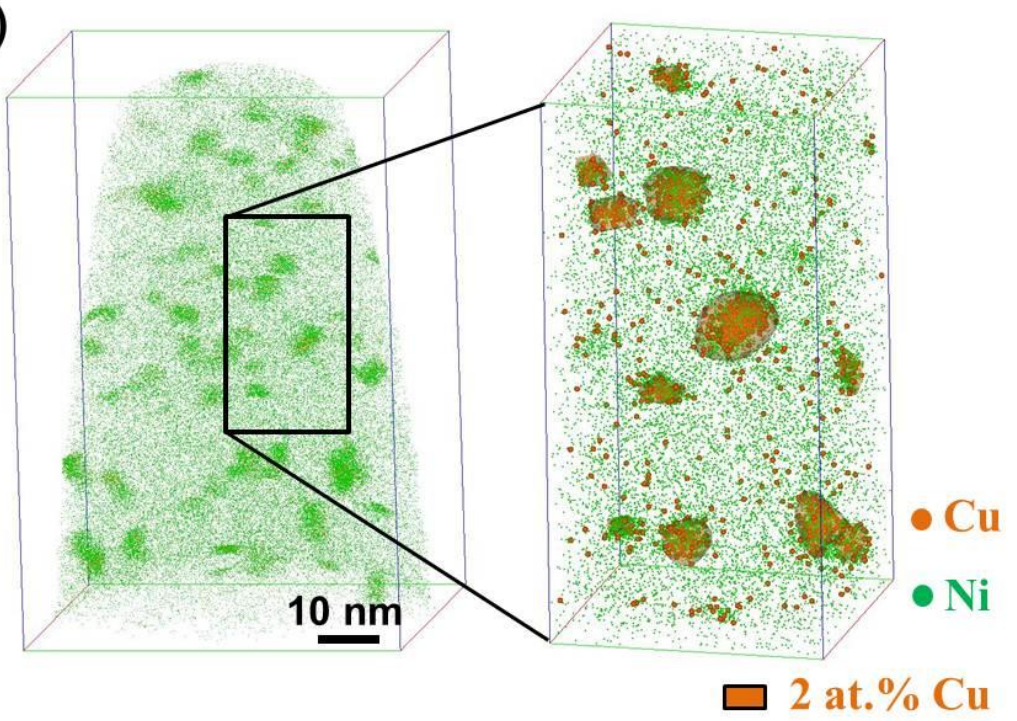

(b)

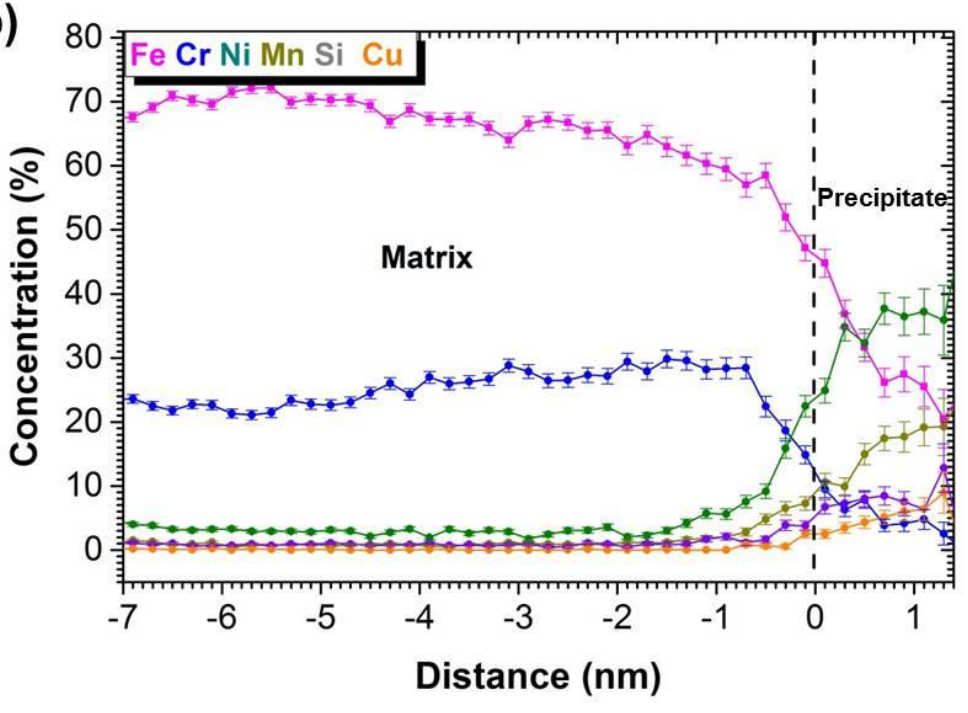

Figure 9. The $\mathrm{Cu}$ and $\mathrm{Ni}$ atom maps of the 2205 alloy aged at $427^{\circ} \mathrm{C}$ for $10,000 \mathrm{hrs}$ (a) and a proxigram analysis of selected isosurfaces of 2 at.\% $\mathrm{Cu}(\mathrm{b})$. 
Table captions:

Table 1. Microhardness of alloy 2101 and 2205 in the ferrite grains for different aging times at $427^{\circ} \mathrm{C}$. The test was performed with a $10 \mathrm{gf}$ load.

\begin{tabular}{ccccc}
\hline Hardness $(\mathrm{HV})$ & $1 \mathrm{hr}$ & $100 \mathrm{hrs}$ & $1000 \mathrm{hrs}$ & $10,000 \mathrm{hrs}$ \\
\hline 2205 alloy & $265.1 \pm 5.0$ & $291.4 \pm 10.5$ & $404.0 \pm 34.4$ & $469.7 \pm 72.4$ \\
2101 alloy & $210 \pm 10.3$ & $209 \pm 8.5$ & $271 \pm 13.4$ & $335 \pm 17.9$ \\
\hline
\end{tabular}

Table 2. The average composition of ferrite grains analyzed by APT.

\begin{tabular}{|c|c|c|c|c|c|c|c|c|c|c|}
\hline Atomic, \% & $\mathrm{Fe}$ & $\mathrm{Cr}$ & $\mathrm{Ni}$ & Mn & $\mathrm{Cu}$ & $\mathrm{Si}$ & Mo & Al & $\mathbf{P}$ & C \\
\hline \multirow{2}{*}{2101 alloy } & 68.12 & 23.69 & 1.13 & 4.48 & 0.19 & 1.94 & 0.14 & 0.03 & 0.07 & 0.06 \\
\hline & \pm 0.05 & \pm 0.05 & \pm 0.01 & \pm 0.02 & \pm 0.01 & \pm 0.01 & \pm 0.01 & \pm 0.002 & \pm 0.003 & \pm 0.003 \\
\hline \multirow{2}{*}{2205 alloy } & 64.07 & 25.76 & 4.22 & 1.65 & 0.24 & 1.08 & 2.11 & 0.004 & 0.08 & 0.08 \\
\hline & \pm 0.04 & \pm 0.04 & \pm 0.02 & \pm 0.01 & \pm 0.01 & \pm 0.01 & \pm 0.02 & \pm 0.001 & \pm 0.003 & \pm 0.002 \\
\hline
\end{tabular}


Table 3: Compositions of the $\alpha$ and $\alpha^{\prime}$ phases after aging between 100 and 10,000 hrs, as evaluated by proximity histograms. The miscibility gap composition was calculated using the TCFE7 database in Thermo-Calc.

\begin{tabular}{|c|c|c|c|c|c|c|c|}
\hline at.\% & phase & $\mathrm{Cr}$ & $\mathbf{N i}$ & Mn & Si & $\mathrm{Cu}$ & Mo \\
\hline \multirow{2}{*}{ 2101-100 hrs } & $\alpha$ & $17.34 \pm 0.29$ & $1.51 \pm 0.02$ & $3.99 \pm 0.03$ & $1.77 \pm 0.02$ & $0.27 \pm 0.01$ & $0.19 \pm 0.01$ \\
\hline & $\alpha^{\prime}$ & $44.56 \pm 0.72$ & $1.13 \pm 0.03$ & $5.36 \pm 0.06$ & $2.35 \pm 0.04$ & $0.17 \pm 0.01$ & $0.19 \pm 0.01$ \\
\hline \multirow{2}{*}{ 2101-1000 hrs } & $\alpha$ & $12.79 \pm 0.10$ & $1.67 \pm 0.02$ & $3.67 \pm 0.03$ & $1.54 \pm 0.02$ & $0.38 \pm 0.01$ & $0.18 \pm 0.01$ \\
\hline & $\alpha^{\prime}$ & $48.25 \pm 0.44$ & $1.01 \pm 0.14$ & $6.52 \pm 0.12$ & $2.92 \pm 0.28$ & $0.12 \pm 0.02$ & $0.21 \pm 0.04$ \\
\hline \multirow{2}{*}{$2101-10,000 \mathrm{hrs}$} & $\alpha$ & $11.19 \pm 0.06$ & $1.62 \pm 0.02$ & $3.67 \pm 0.04$ & $1.59 \pm 0.02$ & $0.36 \pm 0.01$ & $0.20 \pm 0.01$ \\
\hline & $\alpha^{\prime}$ & $70.25 \pm 0.19$ & $0.31 \pm 0.02$ & $6.36 \pm 0.10$ & $2.64 \pm 0.07$ & $0.03 \pm 0.01$ & $0.26 \pm 0.02$ \\
\hline \multirow{2}{*}{$\begin{array}{l}2101 \text { miscibility gap } \\
\text { composition by TCFE } 7\end{array}$} & $\alpha$ & 9.58 & 1.64 & 1.78 & 2.47 & NA & NA \\
\hline & $\alpha^{\prime}$ & 70.27 & 0.07 & 14.78 & 0.03 & NA & NA \\
\hline \multirow{2}{*}{ 2205-100 hrs } & $\alpha$ & $15.50 \pm 0.85$ & $5.78 \pm 0.13$ & $1.73 \pm 0.03$ & $1.08 \pm 0.06$ & $0.75 \pm 0.05$ & $1.83 \pm 0.07$ \\
\hline & $\alpha^{\prime}$ & $40.63 \pm 1.72$ & $3.79 \pm 0.11$ & $2.05 \pm 0.09$ & $1.25 \pm 0.07$ & $0.25 \pm 0.03$ & $2.51 \pm 0.09$ \\
\hline \multirow[t]{2}{*}{ 2205-1000 hrs } & $\alpha$ & $13.20 \pm 0.12$ & $8.83 \pm 0.21$ & $3.22 \pm 0.13$ & $1.65 \pm 0.09$ & $1.17 \pm 0.08$ & $1.65 \pm 0.09$ \\
\hline & $\alpha^{\prime}$ & $51.39 \pm 0.49$ & $2.37 \pm 0.10$ & $1.75 \pm 0.08$ & $1.11 \pm 0.07$ & $0.03 \pm 0.01$ & $3.35 \pm 0.11$ \\
\hline \multirow{2}{*}{$2205-10,000$ hrs } & $\alpha$ & $9.01 \pm 0.18$ & $7.64 \pm 0.16$ & $2.62 \pm 0.10$ & $1.72 \pm 0.08$ & $0.82 \pm 0.05$ & $1.21 \pm 0.07$ \\
\hline & $\alpha^{\prime}$ & $64.15 \pm 0.33$ & $1.51 \pm 0.16$ & $1.43 \pm 0.13$ & $0.78 \pm 0.10$ & $0.05 \pm 0.03$ & $2.92 \pm 0.20$ \\
\hline \multirow{2}{*}{$\begin{array}{l}2205 \text { miscibility gap } \\
\text { composition by TCFE } 7\end{array}$} & $\alpha$ & 7.11 & 5.28 & 0.56 & 1.35 & NA & NA \\
\hline & $\alpha^{\prime}$ & 80.85 & 0.06 & 6.14 & 0.02 & NA & NA \\
\hline
\end{tabular}


Table 4. Statistics and the estimated hardness increase for Ni-Mn-Si-Cu clusters in ferrite of the 2101 and 2205 alloys aged at $427^{\circ} \mathrm{C}$.

\begin{tabular}{|c|c|c|c|c|}
\hline & Volume & Number & Average & Estimated \\
& Fraction & Density & Precipitate & Hardness \\
& $(\%)$ & $\left(\# / \mathbf{m}^{3}\right)$ & Radius (nm) & Increase \\
& & & & $(\mathrm{HV})$ \\
\hline $2101100 \mathrm{Hrs}$ & 0.01 & $1.06 \times 10^{22}$ & 1.33 & 3.5 \\
\hline $2205100 \mathrm{Hrs}$ & 0.72 & $1.25 \times 10^{24}$ & 1.30 & 28.0 \\
\hline $21011000 \mathrm{Hrs}$ & 0.34 & $1.01 \times 10^{23}$ & 1.90 & 32.2 \\
\hline $22051000 \mathrm{Hrs}$ & 0.94 & $3.51 \times 10^{23}$ & 1.68 & 49.0 \\
\hline $210110000 \mathrm{Hrs}$ & 0.56 & $5.74 \times 10^{22}$ & 2.60 & 75.5 \\
\hline $220510000 \mathrm{Hrs}$ & 1.74 & $5.32 \times 10^{23}$ & 2.04 & \\
\hline
\end{tabular}


References:

[1] Gladman T 1999 Precipitation hardening in metals Mater. Sci. Tech. Ser. 15 30-6

[2] Solomon H D, Devine T M and Metals A S f 1982 Duplex Stainless Steels: A Tale of Two Phases:

(Metals Park, Ohio: American Society for Metals)

[3] Gunn R N 1997 Duplex Stainless Steels: Microstructure, Properties and Applications (Abington: Woodhead Publishing)

[4] Hyde J M, Miller M K, Hetherington M G, Cerezo A, Smith G D W and Elliott C M 1995 Spinodal Decomposition in Fe-Cr Alloys - Experimental-study at the atomic-level and comparison with computermodels .3. development of morphology Acta Metall. Mater. 43 3415-26

[5] Tucker J D, Miller M K and Young G A 2015 Assessment of thermal embrittlement in duplex stainless steels 2003 and 2205 for nuclear power applications Acta Mater. 87 15-24

[6] Young G A, Tucker J D, Lewis N, Plesko E and Sander P 2011 Assessment of lean grade duplex stainless steels for nuclear power applications 15th International Conference on Environmental Degradation of Materials in Nuclear Power Systems-Water Reactors 2369-80

[7] Capdevila C, Miller M K, Russell K F, Chao J and González-Carrasco J L 2008 Phase separation in PM 2000 ${ }^{\mathrm{TM}}$ Fe-base ODS alloy: Experimental study at the atomic level Mat. Sci. Eng. A-Struct. 490 277-88 [8] Auger P, Danoix F, Menand A, Bonnet S, Bourgoin J and Guttmann M 1990 Atom probe and transmission electron microscopy study of aging of cast duplex stainless steels Mater. Sci. Tech. Ser. 6 301-13

[9] Deconihout B, Bostel A, Bas P, Chambreland S, Letellier L, Danoix F and Blavette D 1994 Investigation of some selected metallurgical problems with the tomographic atom probe Appl. Surf. Sci. 76 145-54 [10] Mateo A, Llanes L, Anglada M, Redjaimia A and Metauer G 1997 Characterization of the intermetallic G-phase in an AISI 329 duplex stainless steel J. Mater. Sci. 32 4533-40

[11] Li S L, Wang Y L, Zhang H L, Li S X, Zheng K, Xue F and Wang X T 2013 Microstructure evolution and impact fracture behaviors of Z3CN20-09M stainless steels after long-term thermal aging J. Nucl. Mater. $43341-9$

[12] Garfinkel D A, Poplawsky J D, Guo W, Young G A and Tucker J D 2015 Phase separation in lean-grade duplex stainless steel 2101 JOM 67 2216-22

[13] Thompson K, Lawrence D, Larson D J, Olson J D, Kelly T F and Gorman B 2007 In situ site-specific specimen preparation for atom probe tomography Ultramicroscopy 107 131-9

[14] Miller M K and Russell K F 2007 Performance of a local electrode atom probe Surf. Interface Anal. 39 262-7

[15] Miller M K, Hyde J M, Hetherington M G, Cerezo A, Smith G D W and Elliott C M 1995 Spinodal decomposition in Fe-Cr Alloys - Experimental study at the atomic level and comparison with computer models .1. introduction and methodology Acta Metall. Mater. 43 3385-401

[16] Miller M K, Cerezo A, Hetherington M G and Smith G D W 1996 Atom Probe Field Ion Microscopy (Clarendon Press)

[17] Miller M K F and Richard G. 2014 Atom-Probe Tomography (New York: Springer)

[18] Langer J S, Baron M and Miller H D 1975 New computational method in theory of spinodal decomposition Phys. Rev. A 11 1417-29

[19] Zhou J, Odqvist J, Thuvander M and Hedstrom P 2013 Quantitative evaluation of spinodal decomposition in $\mathrm{Fe}-\mathrm{Cr}$ by atom probe tomography and radial distribution function analysis Microsc. Microanal. 19 665-75.

[20] Hellman O C, Vandenbroucke J A, Rusing J, Isheim D and Seidman D N 2000 Analysis of threedimensional atom-probe data by the proximity histogram Microsc. Microanal. 6 437-44 
[21] Capdevila C, Miller M K, Toda I and Chao J 2010 Influence of the $\alpha-\alpha^{\prime}$ phase separation on the tensile properties of Fe-base ODS PM 2000 alloy Mat. Sci. Eng. A-Struct 527 7931-8

[22] Sato A, Tamura K, Ito M, Kato M and Mori T 1993 In situ observation of moving dislocations in a Cu10Ni-6Sn spinodal alloy Acta Metall. Mater. 41 1047-55

[23] Danoix F, Auger P 2000 Atom probe studies of the Fe-Cr system and stainless steels aged at intermediate temperature: A review Mater. Charact., 44 177-201

[24] Pareige C, Novy S, Saillet S and P. Pareige 2011 Study of phase transformation and mechanical properties evolution of duplex stainless steels after long term thermal ageing (>20years) J. Nucl. Mater., 411 90-6.

[25] Zhou J, Odqvist J, Thuvander M, Hertzman S and Hedström P 2012 Concurrent phase separation and clustering in the ferrite phase during low temperature stress aging of duplex stainless steel weldments Acta Mater., 60 5818-27

[26] Miller M K and Russell K F 2007 Embrittlement of RPV steels: An atom probe tomography perspective J. Nucl. Mater. 371 145-60

[27] Miller M K, Russell K F, Sokolov M A and Nanstad R K 2007 APT characterization of irradiated high nickel RPV steels J. Nucl. Mater. 361 248-61

[28] Thuvander M, Zhou J, Odqvist J, Hertzman S and Hedström P 2012 Observations of copper clustering in a $25 \mathrm{Cr}-7 \mathrm{Ni}$ super duplex stainless steel during low-temperature aging under load Phil. Mag. Lett. 92 1-8

[29] Voorhees P W 1985 The theory of Ostwald Ripening J. Stat. Phys. 38 231-52

[30] Zhang P, Li S X and Zhang Z F 2011 General relationship between strength and hardness Mat. Sci. Eng. A-Struct. 529 62-73 